\title{
The sex-specific associations of the aromatase gene with Alzheimer's disease and its interaction with IL10 in the Epistasis Project
}

\author{
Christopher Medway, ${ }^{\star}$, Onofre Combarros ${ }^{2}$, Mario Cortina-Borja ${ }^{3}$, Helen T Butler ${ }^{4}$, \\ Carla A Ibrahim-Verbaas ${ }^{5,6}$, Renée F A G de Bruijn ${ }^{5,6}$, Peter J Koudstaal ${ }^{5}$, Cornelia M van Duijn ${ }^{6}$, \\ M Arfan Ikram ${ }^{5,6,7}$, Ignacio Mateo ${ }^{2}$, Pascual Sánchez-Juan², Michael G Lehmann ${ }^{8}$, Reinhard Heun ${ }^{9,10}$, \\ Heike Kölsch $^{9}$, Panos Deloukas ${ }^{11}$, Naomi Hammond ${ }^{11}$, Eliecer Coto ${ }^{12}$, Victoria Alvarez ${ }^{12}$, Patrick G Kehoe ${ }^{13}$, \\ Rachel Barber ${ }^{13}$, Gordon K Wilcock ${ }^{14}$, Kristelle Brown ${ }^{1}$, Olivia Belbin ${ }^{1}$, Donald R Warden ${ }^{8}$, A David Smith ${ }^{8}$, \\ Kevin Morgan ${ }^{1}$ and Donald J Lehmann ${ }^{8}$
}

Epistasis between interleukin-10 (IL10) and aromatase gene polymorphisms has previously been reported to modify the risk of Alzheimer's disease (AD). However, although the main effects of aromatase variants suggest a sex-specific effect in $A D$, there has been insufficient power to detect sex-specific epistasis between these genes to date. Here we used the cohort of 1757 AD patients and 6294 controls in the Epistasis Project. We replicated the previously reported main effects of aromatase polymorphisms in AD risk in women, for example, adjusted odds ratio of disease for rs $1065778 \mathrm{GG}=1.22$ (95\% confidence interval: 1.01-1.48, $P=0.03$ ). We also confirmed a reported epistatic interaction between IL10 rs 1800896 and aromatase (CYP19A1) rs1062033, again only in women: adjusted synergy factor $=1.94(1.16-3.25,0.01)$. Aromatase, a rate-limiting enzyme in the synthesis of estrogens, is expressed in AD-relevant brain regions, and is downregulated during the disease. IL-10 is an anti-inflammatory cytokine. Given that estrogens have neuroprotective and anti-inflammatory activities and regulate microglial cytokine production, epistasis is biologically plausible. Diminishing serum estrogen in postmenopausal women, coupled with suboptimal brain estrogen synthesis, may contribute to the inflammatory state, that is a pathological hallmark of AD. European Journal of Human Genetics (2014) 22, 216-220; doi:10.1038/ejhg.2013.116; published online 5 June 2013

Keywords: healthy cell bias; C18; dementia; neurodegeneration

\section{INTRODUCTION}

Aromatase catalyses the conversion of $\mathrm{C} 19$ androgens to C18 estrogens. It is expressed in various regions of the human brain. ${ }^{1-5}$ It is found in neurons and in reactive astrocytes. ${ }^{3,5,6}$ Expression of aromatase is altered in Alzheimer's disease (AD). ${ }^{2,4,5}$ Estrogen has many effects in the brain: neurotrophic, neuroprotective (reviewed here $^{7,8}$ ), neurogenerative, ${ }^{9,10}$ antiexitotoxic, ${ }^{11}$ antioxidative (reviewed here ${ }^{12,13}$ ) and anti-inflammatory. ${ }^{14-16}$ In contrast, proinflammatory ${ }^{17}$ and other potentially neurotoxic actions of estrogen, ${ }^{18}$ depending on the context and timing, ${ }^{19,20}$ have also been reported. There are sex differences in these effects. ${ }^{21}$

In view of the importance of aromatase in the synthesis of estrogen and the relevance to AD of estrogen's actions in the brain, variations in the aromatase gene, CYP19A1, may affect the risk of AD. Such variations have been studied in $\mathrm{AD}^{22-27}$ with some contrasting results $^{22,25}$ and with suggestions of sex differences. ${ }^{26,27}$ The results of Butler et al. ${ }^{27}$ were, however, broadly consistent with those of Iivonen et al.,22 although only in women in the former study. Combarros et al. ${ }^{24}$ reported an interaction between variants in CYP19A1 and the gene for interleukin-10 (IL10), consistent with estrogen's reported actions in raising levels of the anti-inflammatory cytokine, interleukin-10 (IL-10). ${ }^{28-31}$

We aimed to replicate the results of Butler et al. ${ }^{27}$ and Combarros et al. ${ }^{24}$ in the Epistasis Project, with 1757 cases of $\mathrm{AD}$ and 6294 controls. ${ }^{32}$

\section{METHODS}

Study population

The Epistasis Project primarily aims to replicate interactions that have been reported to affect the risk of AD. Sample-sets were drawn from narrow geographical regions with relatively homogeneous, Caucasian populations, by seven AD research groups: Bonn, Bristol, Nottingham, Oxford (OPTIMA),

${ }^{1}$ Human Genetics Research, Queens Medical Centre, School of Molecular Medical Sciences, University of Nottingham, Nottingham, UK; ${ }^{2}$ Neurology Service and Centro de Investigación Biomédica en Red sobre Enfermedades Neurodegenerativas(CIBERNED), Marqués de Valdecilla University Hospital (University of Cantabria), Santander, Spain ${ }^{3}$ MRC Centre of Epidemiology for Child Health, Institute of Child Health, University College London, London, UK; ${ }^{4}$ Genomics Laboratory, Wellcome Trust Centre for Human Genetics, University of Oxford, Oxford, UK; ${ }^{5}$ Department of Neurology, Erasmus MC University Medical Center, Rotterdam, the Netherlands; ${ }^{6}$ Department of Epidemiology, Erasmus MC University Medical Center, Rotterdam, the Netherlands; ${ }^{7}$ Department of Radiology, Erasmus MC University Medical Center, Rotterdam, the Netherlands; ${ }^{8}$ Oxford Project to Investigate Memory and Ageing (OPTIMA), University Department of Pharmacology, Oxford, UK; ${ }^{9}$ Department of Psychiatry, University of Bonn, Bonn, Germany; ${ }^{10}$ Department of Psychiatry, Royal Derby Hospital, Derby, UK; ${ }^{11}$ The Wellcome Trust Sanger Institute, Hinxton, UK; ${ }^{12}$ Genética Molecular, Hospital Central de Asturias, Oviedo, Spain; ${ }^{13}$ Dementia Research Group, Institute of Clinical Neurosciences, University of Bristol, Frenchay Hospital, Frenchay Bristol, UK; ${ }^{14 N u f f i e l d ~ D e p a r t m e n t ~ o f ~ M e d i c i n e, ~}$ University of Oxford, Level 4, John Radcliffe Hospital, Oxford, UK

${ }^{*}$ Correspondence: Dr C Medway, Human Genetics Research, Queens Medical Centre, School of Molecular Medical Sciences, University of Nottingham, 1306 A Floor, West Block, Nottingham NG7 2UH, UK. Tel: + 44 (0) 11582 30723; Fax: + 44 (0) 11582 30759; E-mail; mracm@nottingham.ac.uk

Received 19 September 2012; revised 21 January 2013; accepted 14 February 2013; published online 5 June 2013 
Oviedo, Rotterdam and Santander. Sample characteristics by geographical region are given in Supplementary Table 1. All AD cases were diagnosed 'definite' or 'probable' by Consortium to Establish a Registry for Alzheimer's Disease $(\text { CERAD })^{33}$ or National Institute of Neurological and Communicative Diseases and Stroke-Alzheimer's Disease and Related Disorders (NINCDSADRDA) criteria. ${ }^{34} \mathrm{AD}$ cases were sporadic, that is possible autosomal dominant cases were excluded, based on family history. The median ages (interquartile ranges) of $\mathrm{AD}$ cases were 79.0 (73.0-85.2) and of controls were 76.9 (71.3-83.0) years. Research ethical approval was obtained by each of the participating groups (Supplementary Table 2). Comprehensive details of our sample-sets are given elsewhere. ${ }^{32}$

\section{Genotyping}

Genotyping for the six centres other than Rotterdam was performed at the Wellcome Trust Sanger Institute, while the Rotterdam samples were genotyped locally, both as previously described. ${ }^{35}$ For this study, Rotterdam genotyped two single-nucleotide polymorphisms (SNPs), rs1065778 (CYP19A1 Intron 3 $\mathrm{A} / \mathrm{G}$ ) and rs1800896 (IL10-1082 G/A), and imputed three CYP19A1 polymorphisms; rs1062033 (Intron $1 \mathrm{C} / \mathrm{G}$ ), rs700519 (Exon $7 \mathrm{C} / \mathrm{T}$ (Arg264Cys)) and rs10046 (3' UTR T/C). One further SNP, rs1902586, failed quality control and was omitted.

\section{Statistical analysis}

We analysed possible associations by fitting logistic regression models with $\mathrm{AD}$ diagnosis as the outcome variable, controlling for study centre, age, sex and the $\varepsilon 4$ allele of apolipoprotein $\mathrm{E}(A P O E \varepsilon 4)$ in all analyses, using R Version 2.13.0 ( $\mathrm{R}$ Foundation for Statistical Computing, Vienna, Austria). The adjusted synergy factors ${ }^{36}$ were derived from the interaction terms in those models. We controlled for heterogeneity among centres and over-dispersion as described before. $^{35}$ The studied SNPs are shown in Table 1. Comparisons of allelic frequencies between North Europe and North Spain were obtained with Fisher's exact test. Linkage disequilibrium (LD) data were estimated using the R library, genetics (http://cran.r-project.org/web/packages/genetics/ index.html). Power calculations were based on the observed synergy factor values. All tests of significance and power calculations considered $P<0.05$ (two sided) as significant

\section{Bioinformatic analysis}

The possible function of polymorphisms was acquired by exploring the degree of conservation in vertebrates using ECR (Evolutionary Conserved Regions) browser, ${ }^{37}$ and TargetScan for miRNA binding sites. ${ }^{38}$ Additionally, HaploReg ${ }^{39}$ was used to explore the regulatory function (transcription factor binding, methylation patterns) of each SNP and proxies $\left(r^{2}>0.8\right)$ in 1000 Genomes pilot project data (CEU population). ${ }^{40}$ Searching for proxies, LD blocks and calculating pair-wise LD were achieved with SNAP proxy, using 1000 genomes pilot project data $(\mathrm{CEU}){ }^{41}$

\section{RESULTS}

Preliminary analyses

Hardy-Weinberg analysis was performed for the four CYP19A1 SNPs and for IL10-1082 G/A in AD cases and controls genotyped by Sanger and by Rotterdam. None of those 20 results were out of HardyWeinberg equilibrium (all $P>0.05$ ).

Minor allele frequencies in controls for the five polymorphisms in North Europe and North Spain are shown in Table 1. LD between the four CYP19A1 polymorphisms is shown in Table 2. Three SNPs, intron $1 \mathrm{C} / \mathrm{G}$, intron $3 \mathrm{~A} / \mathrm{G}$ and $3^{\prime} \mathrm{UTR} \mathrm{T} / \mathrm{C}$, were in close $\mathrm{LD}$ $\left(r^{2} \geq 0.7\right)$. The LD patterns in North Europe and North Spain were similar (data not shown). Supplementary Table 3 gives the genotype distributions of the five SNPs in AD cases and controls of each of the seven centres.

\section{Main effects of the four CYP19A1 SNPs: overall and stratified by sex}

The adjusted odds ratios of $\mathrm{AD}$ associated with the four CYP19A1 SNPs (including sex-specific effects) are shown in Table 3. The three SNPs that were in LD were each associated with $\mathrm{AD}$ risk, only in women. Supplementary Tables 4 and 5 give the equivalent data for North Europe and North Spain. The main effects in women remained consistent with Table 3 after the OPTIMA data, previously reported by Butler et al. ${ }^{27}$ had been removed; intron 1 GG $(P=0.02$, $O R=1.28 \quad(1.03-1.59)), \quad$ intron 3 GG $(P=0.06, \quad O R=1.21$ $(0.99-1.47))$ and $3^{\prime} \mathrm{UTR}$ TT $(P=0.04, O R=1.22(1.00-1.47))$.

\section{Interaction between CYP19A1 intron 1 GG versus $\mathrm{CC}+\mathrm{CG}$ and IL10-1082 AA + AG versus GG}

Following Combarros et al., ${ }^{24}$ we examined the interaction in $\mathrm{AD}$ risk between CYP19A1 intron 1 GG versus CC+CG and IL10-1082 $\mathrm{AA}+\mathrm{AG}$ versus $\mathrm{GG}$. We replicated the interaction, but only in women (Table 4). We also examined the effect of each of these two genetic factors on the other factor's association with $\mathrm{AD}$ in women (Supplementary Table 6). We found that each factor was only associated with $\mathrm{AD}$ risk in the presence of the other. Consistent with Table 4 , the sex-specific interaction remained significant $(P=0.04$, $O R=1.76(1.02-3.03))$ after the Santander data, previously reported by Combarros et al., ${ }^{24}$ had been removed.

\section{Interactions with sex}

Consistent with the above results (Table 4, and Supplementary Table 6), we found a two-way interaction between CYP19A1 intron $1 \mathrm{C} / \mathrm{G}$ and sex $(P=0.03)$, and a similar trend for the interactions of intron $3 \mathrm{~A} / \mathrm{G}$ and $3^{\prime}$ UTR T/C with sex $(P=0.1)$. We also found a three-way interaction between CYP19A1 intron 1 C/G, IL10-1082 G/A and sex, overall $(P=0.03)$ and in North Europe $(P=0.02)$, but not in North Spain.

\section{DISCUSSION}

Out of the four CYP19A1 SNPs examined, three polymorphisms were associated with AD risk in women; intron $1 \mathrm{C} / \mathrm{G}$ (rs1062033), intron

Table 1 Minor allele frequencies of studied polymorphisms

\begin{tabular}{|c|c|c|c|c|}
\hline \multirow[b]{2}{*}{ Genes } & \multirow[b]{2}{*}{ Polymorphisms } & \multicolumn{3}{|c|}{ Minor allele frequencies in controls } \\
\hline & & North Europe & North Spain & Difference $(p)$ \\
\hline \multirow[t]{4}{*}{ CYP19A1 } & rs1062033 (Intron 1 C/G) & $5004 / 11392=43.9 \%(G)$ & $408 / 1002=40.7 \%(G)$ & 0.054 \\
\hline & rs1065778 (Intron $3 \mathrm{~A} / \mathrm{G}$ ) & $5657 / 11472=49.3 \%(G)$ & $479 / 1028=46.6 \%(G)$ & 0.10 \\
\hline & rs700519 (Exon 7 C/T) (Arg264Cys) & $419 / 11484=3.6 \%(T)$ & $18 / 988=1.8 \%(\mathrm{~T})$ & 0.004 \\
\hline & rs10046 (3' UTR T/C) & $5626 / 11468=49.1 \%(C)$ & $514 / 1006=51.1 \%(C)$ & 0.23 \\
\hline IL 10 & rs1800896 (-1082 G/A) & $5614 / 11390=49.3 \%(A)$ & $566 / 994=56.9 \%(A)$ & $<0.0001$ \\
\hline
\end{tabular}


3 A/G (rs1065778) and 3' UTR T/C (rs10046) (Table 3), all of which were in close LD $\left(r^{2} \geq 0.7\right)$ (Table 2). These results were consistent with Butler et al., ${ }^{27}$ who also found several CYP19A1 polymorphisms associated with $\mathrm{AD}$ in women, including two reported here (intron 3 A/G and $3^{\prime}$ UTR T/C). A rarer $3^{\prime}$-UTR polymorphism (rs4646) within the same LD block $\left(D^{\prime}=1.0\right)$ has also been significantly associated with age at onset in women. ${ }^{26}$

Furthermore, we also replicated the statistical interaction between CYP19A1 intron $1 \mathrm{C} / \mathrm{G}$ and IL10-1082 G/A reported by Combarros et al. ${ }^{24}$ but again only in women (Table 4 ). The identification of a sexspecific interaction in women is an original finding and withstands correction for multiple testing (gender stratification) in the entire data set. Our failure to detect this interaction in men would suggest a sex-specific effect. However, we did not achieve sufficient power in the male analysis to rule out a type- 2 error. We found that each genotype (CYP19A1 Intron 1 GG and IL10-1082 AA + AG) was only associated with increased $\mathrm{AD}$ risk in the presence of the other (Supplementary Table 6), consistent with true epistasis. This may explain why these SNPs individually have shown inconsistent association with AD in the past. ${ }^{25,42,43}$ Reanalysis of the reported main effects and interactions in culled data sets (OPTIMA and Santander samples filtered as relevant) confirms these replications are independent from Butler et al. ${ }^{27}$ and Combarros et al. ${ }^{24}$

An interaction between IL10 and CYP19A1 is biologically plausible in $\mathrm{AD}$. Estrogen and IL-10 both serve to temper inflammation in the brain, ${ }^{44}$ and neuroinflammation is a major pathological hallmark of $\mathrm{AD}^{45}$ Aromatase shows reduced expression in certain $\mathrm{AD}$ brain regions. ${ }^{2}$ Estrogen may do too, but possibly only in women

Table 2 Linkage disequilibrium between four CYP19A1 polymorphisms in controls ${ }^{a}$

\begin{tabular}{lcccc}
\hline & $\begin{array}{c}\text { Intron } \\
1 \mathrm{C} / \mathrm{G}\end{array}$ & $\begin{array}{c}\text { Intron } \\
\text { 3 A/G }\end{array}$ & $\begin{array}{c}\text { Exon 7 C/T } \\
\text { (Arg264Cys) }\end{array}$ & $\begin{array}{c}\text { 3' UTR } \\
\text { T/C }\end{array}$ \\
\hline Intron 1 C/G & $-\ldots-.-$ & 0.975 & 0.957 & 0.957 \\
Intron 3 A/G & 0.764 & $-\ldots .--$ & 0.983 & 0.979 \\
Exon 7 C/T (Arg264Cys) & 0.026 & 0.034 & $-\ldots .--$ & 0.984 \\
3' UTR T/C & $\mathbf{0 . 6 8 9}$ & $\mathbf{0 . 8 9 5}$ & 0.036 &..-- \\
\hline
\end{tabular}

The upper right section gives $D^{\prime}$ values and the lower left gives $r^{2}$

Results in bold indicate $r^{2} \geq 0.7$ (lower left section).

${ }^{a} \mathrm{~A}$ similar pattern was seen in North Europe and North Spain.
$>80$ years old. ${ }^{46}$ Estrogen treatment induces microglial IL-10 expression, and decreases the production of proinflammatory cytokines. ${ }^{14-16,28}$ Conversely estrogen depletion, either through ovariectomy or aromatase knockout, induces proinflammatory cytokine synthesis. ${ }^{44,47}$ The molecular basis of this interaction is complex. Microglia and astrocytes express estrogen receptors (ER $\alpha$, $\mathrm{ER} \beta$ ), and downstream regulation of cytokine transcription via altered phosphorylation of AP-1 interacting proteins has been posited. ${ }^{44,48}$ Alternatively, estrogen may modify the availability of transcription factor $\mathrm{NF} \kappa \mathrm{B}$, either directly or indirectly via the stability of the inhibitory binding protein $(\mathrm{I} \kappa \mathrm{B})$, reducing cytokine and cytokine receptor transcription. ${ }^{49}$

The brain is sexually dimorphic; androgens and estrogens are neuroprotective (reviewed here ${ }^{7,8}$ ) in males and females, respectively, and show sex-specific effects on neural connectivity, development and $\mathrm{A} \beta$ neurotoxicity. ${ }^{21,50}$ In addition to controlling inflammation, estrogen regulates neuronal mitochondrial function and glucose metabolism, vital for cell survival. ${ }^{51}$ Indeed, sex-specific effects are common in $\mathrm{AD}$, including incidence, ${ }^{52}$ neuropathology ${ }^{21}$ and risk factors. ${ }^{53}$ Aromatase variants have previously been shown to have sexspecific effects on hypertension, ${ }^{54}$ which is a risk factor for cognitive decline and $\mathrm{AD}{ }^{55,56}$

Table 4 Interaction in AD risk between CYP19A1 intron 1 GG versus CC + CG and IL10-1082 AA + AG versus GG

\begin{tabular}{|c|c|c|c|c|}
\hline \multirow[b]{2}{*}{ Data set } & \multicolumn{2}{|c|}{ Numbers } & \multirow[b]{2}{*}{ Power ${ }^{\mathrm{a}}$} & \multirow{2}{*}{$\begin{array}{c}\text { Adjusted }{ }^{b} \text { synergy factors } \\
\qquad(95 \% \mathrm{Cl}, P)\end{array}$} \\
\hline & $A D$ & Controls & & \\
\hline \multicolumn{5}{|l|}{ Women } \\
\hline All & 948 & 3553 & $89 \%$ & $1.94(1.16-3.25,0.01)$ \\
\hline North Europe & 656 & 3236 & $82 \%$ & $1.91(1.10-3.32,0.02)$ \\
\hline North Spain & 292 & 317 & $29 \%$ & $1.38(0.35-5.55,0.65)$ \\
\hline \multicolumn{5}{|l|}{ Men } \\
\hline All & 566 & 2585 & $75 \%$ & $0.79(0.39-1.59,0.51)$ \\
\hline North Europe & 407 & 2426 & $66 \%$ & $0.61(0.29-1.31,0.21)$ \\
\hline North Spain & 159 & 159 & $21 \%$ & $1.67(0.30-9.46,0.56)$ \\
\hline
\end{tabular}

Results in bold are significant at $P<0.05$

$\mathrm{AD}$, Alzheimer's disease; $\mathrm{Cl}$, confidence interval.

To detect a synergy factor of 1.9 at $P=0.05$.

${ }^{b}$ Controlling for centre, age, sex and the $\varepsilon 4$ allele of apolipoprotein $E$.

Table 3 Odds ratios of AD associated with four CYP19A1 SNPs

\begin{tabular}{|c|c|c|c|c|c|c|}
\hline \multirow[b]{2}{*}{ SNPS } & \multirow[b]{2}{*}{ Models } & \multicolumn{2}{|c|}{ Numbers } & \multicolumn{3}{|c|}{ Adjusted $^{a}$ odds ratios of $A D(95 \% \mathrm{Cl}, P)$} \\
\hline & & $A D$ & Control & Overall & Women & Men \\
\hline \multirow[t]{2}{*}{ Intron $1 \mathrm{C} / \mathrm{G}^{\mathrm{b}}$} & GG versus & 316 & 1211 & $1.11(0.94-1.31,0.23)$ & $1.28(1.04-1.56,0.02)$ & $0.86(0.64-1.17,0.34)$ \\
\hline & $\mathrm{CC}+\mathrm{CG}$ & 1278 & 4986 & & & \\
\hline \multirow[t]{2}{*}{ Intron $3 \mathrm{~A} / \mathrm{G}^{\mathrm{b}}$} & GG versus & 421 & 1518 & $1.12(0.96-1.30,0.15)$ & $1.22(1.01-1.48,0.03)$ & $0.95(0.73-1.25,0.73)$ \\
\hline & $A A+A G$ & 1264 & 4732 & & & \\
\hline \multirow[t]{2}{*}{ Exon 7 C/T (Arg264Cys) } & $\mathrm{TT}+\mathrm{CT}$ & 91 & 426 & $0.89(0.68-1.18,0.43)$ & $0.90(0.63-1.28,0.56)$ & $0.88(0.54-1.44,0.61)$ \\
\hline & versus CC & 1590 & 5810 & & & \\
\hline \multirow[t]{2}{*}{$3^{\prime}$ UTR T/C } & $\mathrm{TT}$ versus & 472 & 1626 & $1.12(0.96-1.30,0.14)$ & $1.22(1.02-1.46,0.03)$ & $0.96(0.73-1.24,0.74)$ \\
\hline & $\mathrm{CC}+\mathrm{CT}$ & 1209 & 4611 & & & \\
\hline
\end{tabular}

See Supplementary Tables 4 and 5 for the equivalent data for North Europe and North Spain.

$\mathrm{AD}$, Alzheimer's disease; SNP, single-nucleotide polymorphism; $\mathrm{Cl}$, confidence interval.

$\mathrm{AD}$, Alzheimer's disease; SNP, single-nucle
Results in bold are significant at $P<0.05$.

${ }^{a}$ Controlling for centre, age, sex and the $\varepsilon 4$ allele of apolipoprotein $\mathrm{E}$.

${ }^{\mathrm{b}}$ These three SNPs were in close linkage disequilibrium (Table 2). 
While androgens gradually diminish with age in men (bottoming out at 80 years), the menopause marks a rapid drop in the estrogen baseline. ${ }^{46,50}$ Reduced serum estrogen in postmenopausal women has been widely reported to increase the risk of $\mathrm{AD}$ and induces $\mathrm{AD}$-related neuropathological changes. ${ }^{46,57}$ Furthermore, given that brain estrogen levels also include brain-synthesised hormones, ${ }^{1}$ a combination of insufficient local synthesis and postmenopausal decline may be pathologically relevant. Indeed, aromatase is expressed in $\mathrm{AD}$-relevant brain regions, and regions important for memory. ${ }^{58,59}$ Hippocampal aromatase expression is increased in postmenopausal women, but may be decreased in $\mathrm{AD} .{ }^{4}$ Furthermore, $\mathrm{AD}$ pathology in ovariectomised APP23 mice was significantly exacerbated by aromatase knockout. ${ }^{57}$ Also the inhibition of aromatase increases hippocampal $\mathrm{A} \beta$ immunoreactivity in female $3 \mathrm{xTgAD}$ mice only. ${ }^{60}$

However, estrogen has also been reported to be damaging in some contexts. ${ }^{61}$ Treatment with estrogen (hormone replacement therapy) may increase the risk of $\mathrm{AD}$ in women $>65$ years old. ${ }^{62}$ Also, higher levels of estrogen have been reported in women with $\mathrm{AD}$ than in controls. ${ }^{63}$ However, these apparent discrepancies may be reconciled by estrogen showing a 'healthy cell bias'; treatment may be neuroprotective, if commenced shortly after menopause. ${ }^{61}$ Another age-related effect is the report of reduced levels of estrogen in women with $\mathrm{AD}$, but only in those $>80$ years old. ${ }^{46}$ In view of these suggested age-related effects of estrogen's actions, ${ }^{61}$ we also examined whether there were any differences in our results between older and younger postmenopausal women. We found no differences in the main effects of our CYP19A1 SNPs (data not shown), but we did find that the interaction with IL10-1082 was restricted to women $>75$ years old: adjusted synergy factor $=2.29$ (95\% confidence interval: 1.24-4.21, $P=0.008)$; compared with women $<75$ years old: 1.00 $(0.28-3.51,1.00)$. These age differences are consistent with the epidemiological evidence of greater susceptibility of women than men to $\mathrm{AD}$ only in the very old, for example, $>80$ years old. ${ }^{52,64-66}$

Recent meta-analysis suggests that the IL10-1082 A allele is associated with $\mathrm{AD}$ risk, ${ }^{67,68}$ and is correlated with elevated circulating IL-10. ${ }^{42,69}$ The-1082 SNP is located $1058 \mathrm{bp}$ upstream of IL10 in a $6.9 \mathrm{~kb}$ LD block $\left(r^{2}>0.8\right)$ encompassing the entire IL-10 gene. While -1082 itself is not conserved, a conserved $3^{\prime}$ UTR

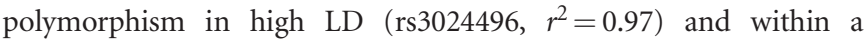
region of miRNA regulation, is an intriguing functional candidate.

Variants within the studied CYP19A1 LD block modify estrogen concentration in postmenopausal women; rs10046 (T/C), rs11575899 $(-/ \mathrm{TCT}))$ and a (TTTA $)_{7}$ microsatellite in intron 4 affect serum estrogen levels. ${ }^{70-72}$ Consistent with this, allelic association between the $3^{\prime}$ UTR (rs10046) C allele and reduced CYP19A1 mRNA expression has previously been established in breast cancer tissue. ${ }^{73}$

Neither intron 1 (rs1062033) nor the assayed CYP19A1 SNPs in LD are conserved in vertebrates, or fall within predicted functional sites (splice site boundaries, miRNA sites). Searching the flanking polymorphisms (1000 Genomes pilot project, CEU) within the $54.4 \mathrm{~kb}$ LD block $\left(r^{2}>0.8\right)$ encompassing the $3^{\prime}$ end of CYP19A1 failed to prioritise any causal variants. This does not rule out a combination of rarer polymorphisms, in imperfect but complete $\operatorname{LD}\left(D^{\prime}=1.0\right)$, having functional effects. Indeed, a fourth polymorphism assayed here, rs700519, is a missense mutation (predicted damaging by SIFT). While this SNP is in LD with the other assayed CYP19A1 polymorphisms $\left(D^{\prime}>0.9\right)$, a low population frequency (Table 1) means we do not have sufficient power to test for the association. However, rs700519 does not affect serum estrogen concentration in postmenopausal women. ${ }^{74}$
In summary, we have replicated the epistatic interaction between IL10 and CYP19A1 polymorphisms, which increases the risk of AD. Furthermore, we have identified a sex-specific effect limited to females. Although the specific function of these mutations is unknown, they may act as a proxy for reduced IL-10 and estrogen synthesis, which are anti-inflammatory and neuroprotective agents, and relevant to $\mathrm{AD}$.

\section{CONFLICT OF INTEREST}

The authors declare no conflict of interest.

\section{ACKNOWLEDGEMENTS}

We are most grateful to the Moulton Charitable Foundation for a grant to fund the Epistasis Project, to all those who have provided support for the individual clinical studies, to Alzheimer's Research UK and to the Thomas Willis Oxford Brain Collection for tissue for DNA extraction. GKW and DRW are partly funded by NIHR Biomedical Research Centre Oxford. MCB benefited from funding from the Medical Research Council. The Rotterdam Study is supported by the Erasmus Medical Center and Erasmus University, Rotterdam, The Netherlands Organization for Scientific Research (NWO), Netherlands Organization for the Health Research and Development (ZonMw), the Research Institute for Diseases in the Elderly (RIDE), The Netherlands Genomics Initiative, the Ministry of Education, Culture and Science, the Ministry for Health, Welfare and Sports, the European Commission (DG XII) and the Municipality of Rotterdam. The generation and management of GWAS genotype data for the Rotterdam Study is supported by the Netherlands Organisation of Scientific Research NWO Investments (nr. 175.010.2005.011, 911-03-012). The contribution of inhabitants, general practitioners and pharmacists of the Ommoord district to the Rotterdam Study is gratefully acknowledged.

1 Stoffel-Wagner B: Neurosteroid biosynthesis in the human brain and its clinical implications. Ann N Y Acad Sci 2003; 1007: 64-78.

2 Ishunina TA, Van Beurden D, Van der Meulen G et al: Diminished aromatase immunoreactivity in the hypothalamus, but not in the basal forebrain nuclei in Alzheimer's disease. Neurobiol Aging 2005; 26: 173-194.

3 Yague JG, Muñoz A, De Monasterio-Schrader P, Defelipe J, Garcia-Segura LM, Azcoitia I: Aromatase expression in the human temporal cortex. Neuroscience 2006; 138: 389-401.

4 Ishunina TA, Fischer DF, Swaab DF: Estrogen receptor alpha and its splice variants in the hippocampus in aging and Alzheimer's disease. Neurobiol Aging 2007; 28: 1670-1681.

5 Luchetti S, Bossers K, Van de Bilt S et al: Neurosteroid biosynthetic pathways changes in prefrontal cortex in Alzheimer's disease. Neurobiol Aging 2011; 32: 1964-1976.

6 Azcoitia I, Sierra A, Veiga S, Garcia-Segura LM: Aromatase expression by reactive astroglia is neuroprotective. Ann N Y Acad Sci 2003; 1007: 298-305.

7 Brann DW, Dhandapani K, Wakade C, Mahesh VB, Khan MM: Neurotrophic and neuroprotective actions of estrogen: basic mechanisms and clinical implications. Steroids 2007; 72: 381-405.

8 Fiocchetti M, Ascenzi P, Marino M: Neuroprotective effects of $17 \beta$-estradiol rely on estrogen receptor membrane initiated signals. Front Physiol 2012; 3: 73.

9 Wang JM, Liu L, Brinton RD: Estradiol-17beta-induced human neural progenitor cell proliferation is mediated by an estrogen receptor beta-phosphorylated extracellularly regulated kinase pathway. Endocrinology 2008; 149: 208-218.

10 Shao B, Cheng Y, Jin K: Estrogen, neuroprotection and neurogenesis after ischemic stroke. Curr Drug Targets 2012; 13: 188-198.

11 Liang Z, Valla J, Sefidvash-Hockley S, Rogers J, Li R: Effects of estrogen treatment on glutamate uptake in cultured human astrocytes derived from cortex of Alzheimer's disease patients. J Neurochem 2002; 80: 807-814.

12 Simpkins JW, Yi KD, Yang S-H, Dykens JA: Mitochondrial mechanisms of estrogen neuroprotection. Biochim Biophys Acta 2010; 1800: 1113-1120.

13 Numakawa T, Matsumoto T, Numakawa Y, Richards M, Yamawaki S, Kunugi H: Protective action of neurotrophic factors and estrogen against oxidative stressmediated neurodegeneration. J Toxicol 2011; 2011: 405194.

14 Kramer PR, Kramer SF, Guan G: 17 beta-estradiol regulates cytokine release through modulation of CD16 expression in monocytes and monocyte-derived macrophages. Arthritis Rheum 2004; 50: 1967-1975.

15 Cvoro A, Tatomer D, Tee M-K, Zogovic T, Harris HA, Leitman DC: Selective estrogen receptor-beta agonists repress transcription of proinflammatory genes. J Immunol 2008; 180: 630-636. 
16 Murphy AJ, Guyre PM, Pioli PA: Estradiol suppresses NF-kappa B activation through coordinated regulation of let-7a and miR-125b in primary human macrophages. J Immunol 2010; 184: 5029-5037.

17 Bengtsson AK, Ryan EJ, Giordano D, Magaletti DM, Clark EA: 17beta-estradiol (E2) modulates cytokine and chemokine expression in human monocyte-derived dendritic cells. Blood 2004; 104: 1404-1410.

18 Azcoitia I, Arevalo M-A, De Nicola AF, Garcia-Segura LM: Neuroprotective actions of estradiol revisited. Trends Endocrinol Metab 2011; 22: 467-473.

19 Selvamani A, Sohrabji F: Reproductive age modulates the impact of focal ischemia on the forebrain as well as the effects of estrogen treatment in female rats. Neurobio Aging 2010; 31: 1618-1628.

20 Selvamani A, Sohrabji F: The neurotoxic effects of estrogen on ischemic stroke in olde female rats is associated with age-dependent loss of insulin-like growth factor- 1 . J Neurosci 2010; 30: 6852-6861.

21 Gillies GE, McArthur S: Estrogen actions in the brain and the basis for differential action in men and women: a case for sex-specific medicines. Pharmacol Rev 2010; 62: 155-198.

22 livonen S, Corder E, Lehtovirta M et al: Polymorphisms in the CYP19 gene confer increased risk for Alzheimer disease. Neurology 2004; 62: 1170-1176.

23 Combarros O, Riancho JA, Infante J et al: Interaction between CYP19 aromatase and butyrylcholinesterase genes increases Alzheimer's disease risk. Dement Geriatr Cogn Disord 2005; 20: 153-157.

24 Combarros O, Sánchez-Juan P, Riancho JA et al: Aromatase and interleukin-10 genetic variants interactively modulate Alzheimer's disease risk. J Neural Transm 2008; 115 863-867.

25 Huang R, Poduslo SE: CYP19 haplotypes increase risk for Alzheimer's disease. J Med Genet 2006; 43: e42.

26 Corbo RM, Gambina G, Ulizzi L, Moretto G, Scacchi R: Genetic variation of CYP19 (aromatase) gene influences age at onset of Alzheimer's disease in women. Dement Geriatr Cogn Disord 2009; 27: 513-518.

27 Butler HT, Warden DR, Hogervorst E, Ragoussis J, Smith AD, Lehmann DJ: Association of the aromatase gene with Alzheimer's disease in women. Neurosci Lett 2010; 468 202-206.

28 Dimayuga FO, Reed JL, Carnero GA et al: Estrogen and brain inflammation: effects on microglial expression of MHC, costimulatory molecules and cytokines. J Neuroimmunol 2005; 161: 123-136.

29 Yates MA, Li Y, Chlebeck PJ, Offner H: GPR30, but not estrogen receptor-alpha, is crucial in the treatment of experimental autoimmune encephalomyelitis by oral ethiny estradiol. BMC Immunol 2010; 11: 20.

30 De Medeiros SF, Maitelli A: Cellular and humoral immune responses after short-term oral hormone therapy in postmenopausal women. Climacteric 2011; 14: 677-682.

31 Velders M, Schleipen B, Fritzemeier KH, Zierau O, Diel P: Selective estrogen receptor$\beta$ activation stimulates skeletal muscle growth and regeneration. FASEB J 2012; 26: 1909-1920.

32 Combarros O, Van Duijn CM, Hammond $\mathrm{N}$ et al: Replication by the Epistasis Project of the interaction between the genes for IL- 6 and IL-10 in the risk of Alzheimer's disease. J Neuroinflammation 2009; 6: 22.

33 Mirra SS, Heyman A, McKeel D et al: The Consortium to Establish a Registry for Alzheimer's Disease (CERAD). Part II. Standardization of the neuropathologic assessment of Alzheimer's disease. Neurology 1991; 41: 479-486.

34 McKhann G, Drachman D, Folstein M, Katzman R, Price D, Stadlan EM: Clinica diagnosis of Alzheimer's disease: report of the NINCDS-ADRDA Work Group under the auspices of Department of Health and Human Services Task Force on Alzheimer's Disease. Neurology 1984; 34: 939-944.

35 Kölsch H, Lehmann DJ, Ibrahim-Verbaas CA et al: Interaction of insulin and PPAR- $\alpha$ genes in Alzheimer's disease: the Epistasis Project. J Neural Transm 2012; 119: 473-479.

36 Cortina-Borja M, Smith AD, Combarros O, Lehmann DJ: The synergy factor: a statistic to measure interactions in complex diseases. BMC Res Notes 2009; 2: 105.

37 Ovcharenko I, Nobrega MA, Loots GG, Stubbs L: ECR Browser: a tool for visualizing and accessing data from comparisons of multiple vertebrate genomes. Nucleic Acids Res 2004; 32: W280-W286.

38 Lewis BP, Burge CB, Bartel DP: Conserved seed pairing, often flanked by adenosines, indicates that thousands of human genes are microRNA targets. Cell 2005; 120: 15-20.

39 Ward LD, Kellis M: HaploReg: a resource for exploring chromatin states, conservation, and regulatory motif alterations within sets of genetically linked variants. Nucleic Acids Res 2012; 40: D930-D934.

401000 Genomes Project Consortium. A map of human genome variation from population-scale sequencing. Nature 2010; 467: 1061-1073.

41 Johnson AD, Handsaker RE, Pulit SL, Nizzari MM, O'Donnell CJ, De Bakker PIW: SNAP: a web-based tool for identification and annotation of proxy SNPs using HapMap. Bioinformatics 2008; 24: 2938-2939.

$42 \mathrm{Ma} \mathrm{SL}$, Tang NLS, Lam LCW, Chiu HFK: The association between promoter polymorphism of the interleukin-10 gene and Alzheimer's disease. Neurobiol Aging 2005; 26: 1005-1010.

43 Bagnoli S, Cellini E, Tedde A et al: Association of IL10 promoter polymorphism in Italian Alzheimer's disease. Neurosci Lett 2007; 418: 262-265.

44 Członkowska A, Ciesielska A, Gromadzka G, Kurkowska-Jastrzebska I: Gender differences in neurological disease: role of estrogens and cytokines. Endocrine 2006; 29: 243-256.
45 Wyss-Coray T: Inflammation in Alzheimer disease: driving force, bystander or beneficia response? Nat Med 2006; 12: 1005-1015.

46 Rosario ER, Chang L, Head EH, Stanczyk FZ, Pike CJ: Brain levels of sex steroid hormones in men and women during normal aging and in Alzheimer's disease. Neurobiol Aging 2011; 32: 604-613

47 Brown CM, Mulcahey TA, Filipek NC, Wise PM: Production of proinflammatory cytokines and chemokines during neuroinflammation: novel roles for estrogen receptors alpha and beta. Endocrinology 2010; 151: 4916-4925.

48 Srivastava S, Weitzmann MN, Cenci S, Ross FP, Adler S, Pacifici R: Estrogen decreases TNF gene expression by blocking JNK activity and the resulting production of C-Jun and JunD. J Clin Invest 1999; 104: 503-513.

49 Bryant DN, Sheldahl LC, Marriott LK, Shapiro RA, Dorsa DM: Multiple pathways transmit neuroprotective effects of gonadal steroids. Endocrine 2006; 29: 199-207.

50 Vest RS, Pike CJ: Gender, sex steroid hormones, and Alzheimer's disease. Horm Behav 2012; 63: 301-307.

51 Brinton RD: Estrogen regulation of glucose metabolism and mitochondrial function: therapeutic implications for prevention of Alzheimer's disease. Adv Drug Deliv Rev 2008; 60: 1504-1511

52 Letenneur L, Gilleron V, Commenges D, Helmer C, Orgogozo JM, Dartigues JF: Are sex and educational level independent predictors of dementia and Alzheimer's disease? Incidence data from the PAQUID project. I Neurol Neurosurg Psychiatry 1999; 66 : 177-183.

53 Azad NA, Al Bugami M, Loy-English I: Gender differences in dementia risk factors. Gender medicine 2007; 4: 120-129.

54 Ramirez-Lorca R, Grilo A, Martinez-Larrad MT et al: Sex and body mass index specific regulation of blood pressure by CYP19A1 gene variants. Hypertension 2007; 50: 884-890.

55 Elias MF, Wolf PA, D'Agostino RB, Cobb J, White LR: Untreated blood pressure level is inversely related to cognitive functioning: the Framingham Study. Am J Epidemiol 1993; 138: 353-364

56 Kivipelto M, Helkala E-L, Laakso MP et al: Apolipoprotein E epsilon4 allele, elevated midlife total cholesterol level, and high midlife systolic blood pressure are independent risk factors for late-life Alzheimer disease. Ann Intern Med 2002; 137: 149-155.

57 Yue X, Lu M, Lancaster T et al: Brain estrogen deficiency accelerates Abeta plaque formation in an Alzheimer's disease animal model. Proc Natl Acad Sci USA 2005; 102: 19198-19203.

58 Kretz O, Fester L, Wehrenberg U et al: Hippocampal synapses depend on hippocampal estrogen synthesis. J Neurosci 2004; 24: 5913-5921.

59 Mukai H, Kimoto T, Hojo Y et al: Modulation of synaptic plasticity by brain estrogen in the hippocampus. Biochim Biophys Acta 2010; 1800: 1030-1044.

60 Overk CR, Lu P-Y, Wang Y-T et al: Effects of aromatase inhibition versus gonadectomy on hippocampal complex amyloid pathology in triple transgenic mice. Neurobiol Dis 2012; 45: 479-487.

61 Brinton RD: The healthy cell bias of estrogen action: mitochondrial bioenergetics and neurological implications. Trends Neurosci 2008; 31: 529-537.

62 Craig MC, Maki PM, Murphy DGM: The Women's Health Initiative Memory Study: findings and implications for treatment. Lancet Neurol 2005; 4: 190-194.

63 Hogervorst E, Bandelow S: The controversy over levels of sex steroids in cases with Alzheimer's disease. J Neuroendocrinol 2004; 16: 93-94.

64 Fratiglioni L, Viitanen M, Von Strauss E, Tontodonati V, Herlitz A, Winblad B: Very old women at highest risk of dementia and Alzheimer's disease: incidence data from the Kungsholmen Project, Stockholm. Neurology 1997; 48: 132-138.

65 Ott A, Breteler MM, Van Harskamp F, Stijnen T, Hofman A: Incidence and risk of dementia. The Rotterdam Study. Am J Epidemiol 1998; 147: 574-580.

66 Matthews F, Brayne C: The incidence of dementia in England and Wales: findings from the five identical sites of the MRC CFA Study. PLoS Med 2005; 2: e193.

67 Zhang Y, Zhang J, Tian C et al: The -1082G/A polymorphism in IL-10 gene is associated with risk of Alzheimer's disease: a meta-analysis. J Neurol Sci 2011; 303 133-138.

68 Di Bona D, Rizzo C, Bonaventura G, Candore G, Caruso C: Association between interleukin-10 polymorphisms and Alzheimer's disease: a systematic review and metaanalysis. J Alzheimers Dis 2012; 29: 751-759.

69 Turner DM, Williams DM, Sankaran D, Lazarus M, Sinnott PJ, Hutchinson IV: An investigation of polymorphism in the interleukin-10 gene promoter. Eur $J$ Immunogenet 1997; 24: 1-8.

70 Dunning AM, Dowsett M, Healey CS et al: Polymorphisms associated with circulating sex hormone levels in postmenopausal women. J Natl Cancer Inst 2004; 96: 936-945.

71 Tworoger SS, Chubak J, Aiello EJ et al: Association of CYP17, CYP19, CYP1B1, and COMT polymorphisms with serum and urinary sex hormone concentrations in postmenopausal women. Cancer Epidemiol Biomarkers Prev 2004; 13: 94-101.

72 Haiman CA, Dossus L, Setiawan VW et al: Genetic variation at the CYP19A1 locus predicts circulating estrogen levels but not breast cancer risk in postmenopausal women. Cancer Res 2007; 67: 1893-1897.

73 Kristensen VN, Harada N, Yoshimura N et al: Genetic variants of CYP19 (aromatase) and breast cancer risk. Oncogene 2000; 19: 1329-1333.

74 Wang JZ, Deogan MS, Lewis JR et al: A non-synonymous coding change in the CYP19A1 gene Arg264Cys (rs700519) does not affect circulating estradiol, bone structure or fracture. BMC Med Genet 2011; 12: 165.

Supplementary Information accompanies this paper on European Journal of Human Genetics website (http://www.nature.com/ejhg) 